\title{
Variations of the circumflex humeral arteries: a cadaveric study
}

\author{
Mohamed Elajnaf $^{1,2}$ (D), Abduelmenem Alashkham ${ }^{1}$ (D) \\ 'Anatomy, School of Biomedical Sciences, Edinburgh Medical School, University of Edinburgh, Edinburgh, UK \\ ${ }^{2}$ Leicester General Hospital, University Hospitals of Leicester NHS Trust, Gwendolen Road, Leicester, UK
}

\begin{abstract}
Objectives: Surgery is the main treatment option of both anatomical and surgical neck humeral fractures, which could result in damage to the circumflex humeral vessels. Current research studies have found that vascular supply to the shoulder is variable. However, the incidence of these variations and how they can affect the blood supply to the shoulder region is still under investigation. The aim of this study is to identify possible variation patterns of the circumflex humeral vessels.

Methods: A total of 10 shoulders (3 males, 2 females; average age of 68.8 years) were dissected in Anatomy, University of Edinburgh, under the regulation of the Human Tissue (Scotland) Act 2006. Each shoulder was dissected, and tissues were removed to identify the axillary artery and its branches.

Results: The anterior and posterior circumflex humeral arteries were observed to arise as single branches from the 3rd part of the axillary artery in $70 \%(n=7)$ and $80 \%(n=8)$, respectively. In one cadaver, the posterior circumflex humeral artery (PCHA) arose from the subscapular artery in one side $(10 \%, n=1)$ and from the profunda brachii artery on the contralateral side $(10 \%$, $n=1)$. In the remaining $10 \%(n=1)$, the anterior circumflex humeral artery $(A C H A)$ was found as a branch from the PCHA, with the latter being a direct branch from the 3rd part of the axillary artery.
\end{abstract}

Conclusion: Knowledge and awareness of these variations is essential to not only suspect, diagnose and treat possible complications of common fractures and dislocations in the region, but also to prevent iatrogenic injury.

Keywords: anatomical variation; axillary artery; circumflex humeral arteries; profunda brachii artery; quadrangular space

Anatomy 2020;14(3):171-176 @2020 Turkish Society of Anatomy and Clinical Anatomy (TSACA)

\section{Introduction}

The axillary artery is a large blood vessel that supplies the lateral thorax, axilla and upper limb. It is formed as a continuation of the subclavian artery at the lateral border of the first rib. Anatomically, it is divided into three parts by the pectoralis minor and provides branches from each part that supply the pectoral region, lateral thoracic wall, the shoulder girdle and mammary gland. ${ }^{[1]}$ The third part of the axillary artery starts at the lateral border of pectoralis minor and terminates at the inferior border of teres major to become the brachial artery. Classically, there are three branches of the third part of the axillary artery, which are the anterior and posterior circumflex humeral arteries and the subscapular artery. ${ }^{[1-3]}$ According to Standring, ${ }^{[1]}$ the anterior circumflex humeral artery (ACHA) arises at the distal border of subscapularis and runs horizontally posterior to coracobrachialis and the short head of biceps brachii. It reaches the surgical neck of the humerus anteriorly and continues laterally inferior to the long head of biceps and deltoid to anastomose with the terminal branches of the posterior circumflex humeral artery (PCHA). The PCHA, which is the larger of the two circumflex humeral branches, additionally originates at the distal border of subscapularis. However, it runs posteriorly through the quadrangular space accompanied by the axillary nerve. It circumflexes around the surgical neck of the humerus to form an anastomosis with branches of the ACHA. ${ }^{[1,3]}$

A series of studies has reported variations in the origin of the anterior and posterior circumflex humeral arteries. The ACHA was observed to arise from the profunda brachii

This study was an oral presentation at the Anatomical Society Winter Meeting, 18th - 20th December 2017, Dundee, Scotland, UK. 
artery $(\mathrm{PBA}){ }^{[4-6]}$ Whereas Patnaik et al. ${ }^{[5]}$ reported that the ACHA was found to arise from the brachial artery. A study conducted by Saeed et al. ${ }^{[7]}$ involving 106 formalin-fixed adult human cadavers concluded that an anomalous topographic pattern of the subclavian-axillary arterial system was found in $7.5 \%$ of the samples. The same authors found that the ACHA and PCHA originated from the second part of the axillary artery in $1.9 \%$, which was described as a thoracohumeral trunk giving rise to the lateral thoracic, circumflex humeral, subscapular and thoracodorsal arteries. ${ }^{[7]}$

Classical anatomy of the PCHA is described as arising from the third part of the axillary artery ${ }^{[4,5,8]}$ However, Huelke et $\mathrm{al}^{\left[{ }^{[4]}\right.}$ reported that this was the case in only $67.5 \%$ of the specimens. They found that the PCHA originated directly from the subscapular artery and the PBA in $15.2 \%$ and $2.8 \%$ respectively. ${ }^{[4]}$ In contrast, Hartley and Marquez, ${ }^{[0]}$ dissected 48 cadaveric upper limbs and reported that the traditional "textbook" branching pattern (Type 1) was only observed in $56 \%$ of the sample. Whereas in more than $6 \%$ of the cases, the PCHA was found to arise from the subscapular artery. ${ }^{\left[{ }^{[0]}\right.}$ Based on multidetector-row computed tomography angiography of 62 upper extremities, Hattori et al. ${ }^{[10]}$ highlighted that the classic origin and branching patterns of the subscapular artery and the PCHA were only observed in $33.9 \%$ of cases. Other very rare patterns of origin of the PCHA arising from the lateral thoracic artery, brachial artery and circumflex scapular artery have also been reported. ${ }^{[8,1]}$

The incidence of variations of the circumflex humeral arteries is still under investigation, as the branching pattern has shown considerable variation. It is fundamental to report all variations of the ACHA and PCHA as it provides guidance on rare symptomatology of upper limb neurovascular pathology, such as axillary artery occlusion and quadrilateral space syndrome. Additionally, it helps anticipate surgical outcome related to trauma or fixation surrounding the surgical neck of the humerus and expands knowledge for surgical exploration of the region to avoid iatrogenic vascular injury. Therefore, the aim of this study was to identify the variational patterns of the ACHA and PCHA to aid the surgeon, anatomist and radiologist regarding the possible prevalence of this variation.

\section{Materials and Methods}

Five Genelyn-fixed cadavers ( 3 males and 2 females, average age 68.8 years), with 10 shoulders $(n=10)$, were dissected. The cadaveric specimens were obtained from Anatomy, University of Edinburgh, which is under ethical regulation of the Human Tissue (Scotland) Act 2006. Each specimen was clear from any signs of trauma or sur- gery at the shoulder or axillary region, with the cause of death unrelated to the region being studied. Dissection was performed according to Grant's Dissector, with a full exposure of the shoulder, axilla and upper arm. ${ }^{[12]}$ The skin and subcutaneous tissues and muscles around the shoulder have been dissected, appreciated then removed. The axillary artery and its branches were dissected, identified and recorded.

\section{Results}

The axillary artery and its branches were detected and recorded in all 10 shoulders. A full exposure and record of the axillary artery and its branches have been performed. The circumflex humeral arteries branched as follows:

- ACHA as single branch from the third part of the axillary artery in $70 \%(\mathrm{n}=7)$.

- PCHA as single branch from the third part of the axillary artery in $80 \%(\mathrm{n}=8)$.

- ACHA from the PCHA in 10\% (n=1) (Figure 1).

- PCHA from the subscapular artery in $10 \% \quad(n=1)$ (Figure 2).

- PCHA from the PBA in 10\% ( $\mathrm{n}=1)$ (Figure 3).

In all the specimens, the ACHA coursed laterally posterior to both the short head of biceps brachii and coracobrachialis to reach the surgical neck of the humerus (Figure 1). In 90\% ( $\mathrm{n}=9)$ of the specimens, the PCHA passed posteriorly through the quadrangular space (Figure 2), whereas in 10\% ( $\mathrm{n}=1)$, after arising from the PBA, it ran superolaterally between the long and lateral heads of triceps (Figure 3) towards the surgical neck of the humerus to anastomose with the ACHA.

\section{Discussion}

The origin of ascending branch of the ACHA is quite variable ${ }^{[13-19]}$ (Table 1) and clinically it the is single most important artery in supplying the humeral head..$^{[20-21]}$ Studies have shown that surgical complications related to proximal humeral fracture (PHF) repair can adversely affect the blood supply to the head of the humerus. In a systematic review by Lanting et al. ${ }^{[2]}$ involving 2155 patients, who completed follow up with an average age of 62.8 years, open reduction and internal fixation (ORIF) was found to cause avascular necrosis of the humeral head in $37 \%$ of the patients. The ACHA is typically a branch from the third part of the axillary artery and runs laterally in a horizontal direction to reach the surgical neck of the humerus. ${ }^{[1]}$ The current study has shown that in only $90 \%$ this classical pattern is observed with the ACHA arising directly from the third part of the axillary artery (Table $\mathbf{1}$ ). However, in $10 \%$ it aroused as a branch from the PCHA 
(Figure 1). It can be argued that variations in the ACHA origin may contribute to the risk of developing avascular necrosis in patients with PHF. Xu et al ${ }^{[23]}$ demonstrated in a meta-analysis involving seven studies with a total number of 291 patients that plate fixation was associated with a higher rate of avascular necrosis than conservative treatment $(\mathrm{p}=0.019)$. This highlights the importance of recognising that anatomical variations may contribute to clinical outcome related to PHF.

Observations from a study on branches of the axillary artery involving 178 sides by Hulke et al., ${ }^{[4]}$ demonstrated that $80.3 \%$ arise directly from the third part of the axillary artery. The same study reported that in $11.2 \%$ the ACHA arises as a common trunk with the PCHA from the third part of the axillary artery and in $1.7 \%$ it arises from the PBA. Other studies have shown similar findings with the most common origin of the ACHA being the third part of the axillary artery. ${ }^{\left[{ }^{[j}\right.}$ Rarely, it may arise from the PBA and the second part of the axillary artery, or it can even be absent. ${ }^{[4-6]}$ Interestingly, Brooks et al., ${ }^{[21]}$ had demonstrated the effects of simulated PHF on the arterial supply of the humeral head. In their study with barium sulphate perfusion after simulated PHF in 16 cadavers, they report that blood supply was preserved after the fracture. ${ }^{[2]]}$ However, anastomotic branches with the posteromedial vessels from the PCHA may have a role in preserving the vascularity of the humeral head in certain types of fractures.

Embryologically, the lateral branch of the seventh intersegmental artery (later will become the subclavian artery) is thought to form the arterial trunk that supplies the upper limb during fetal development. ${ }^{[1]}$ The principal arteries and anastomoses appear according to a sequence and regression of some networks that were initially functionally dominant can lead to anatomical variations and vascular anomalies. ${ }^{[1]}$ The continuation of the subclavian artery, the axial artery, persists as the axillary and brachial arteries, which supply the upper limb. ${ }^{[24]}$ A typical axillary

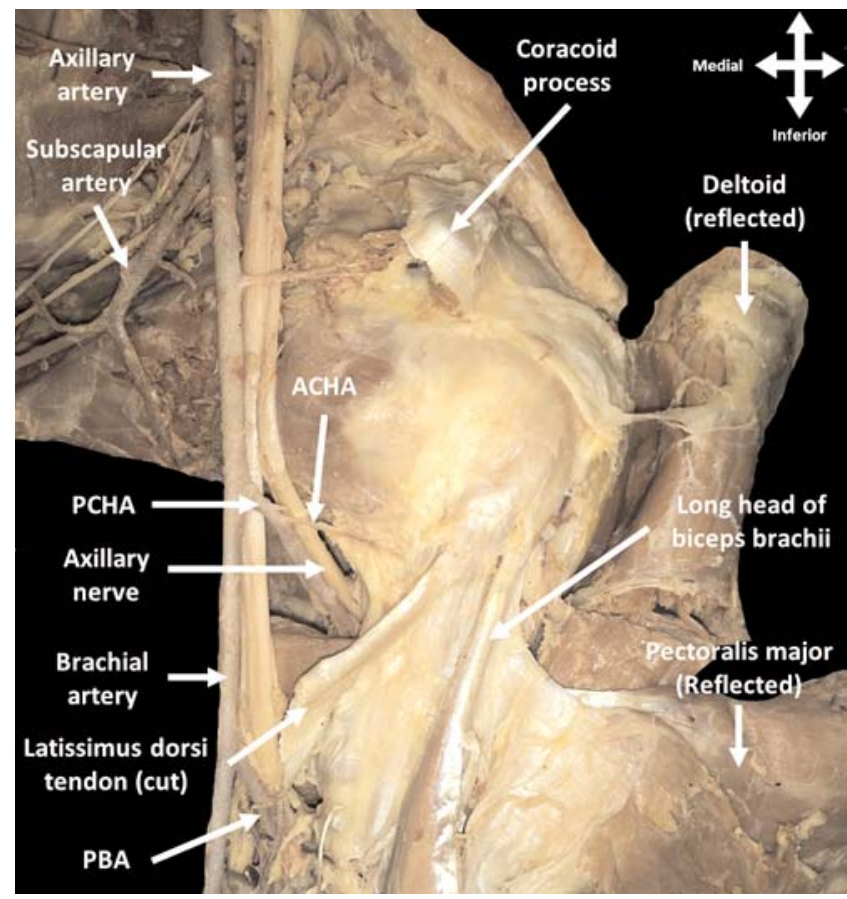

Figure 1. Anterior view of the left shoulder after dissection with exposure of the axillary artery and its branches. The anterior circumflex humeral artery (ACHA) is seen arising from the posterior circumflex humeral artery (PCHA). PBA: Profunda brachii artery.

artery gives origin to six branches: superior thoracic, thoraco-acromial, lateral thoracic, subscapular and anterior and posterior circumflex humeral arteries with other unnamed branches that might additionally be present. ${ }^{[4]}$ However, the classical description of the axillary artery branches only represents $10 \%$ of cases and not all variants incidence is reported in the current literature. ${ }^{[25]}$

Variations in the origin of the PCHA are also common (Table 2). The common branching pattern of the PCHA is of the classical type arising from the third part of the axillary artery. ${ }^{[4,5,8-10]}$ As with the ACHA, variations of the

Table 1

Frequency of distribution of the origin of the ACHA.

\begin{tabular}{|c|c|c|c|c|c|c|}
\hline \multirow[b]{2}{*}{ Studies } & \multicolumn{6}{|c|}{ Origin of $\mathrm{ACHA}(\%)$} \\
\hline & 2nd part of AA & 3rd part of AA & PBA & BA & PCHA & Others \\
\hline Hulke et al. ${ }^{[4]}$ & & 80.3 & 1.7 & & & 0.65 \\
\hline Saeed et al. ${ }^{[7]}$ & 1.9 & 3.8 & & & & \\
\hline Bhat et al. ${ }^{[13]}$ & $C R$ & & & & & \\
\hline Patnaik et al..$^{[5]}$ & & & 2 & 2 & & \\
\hline Bagoji et al. ${ }^{[6]}$ & & & $C R$ & & & \\
\hline Present study & & 90 & & & 10 & \\
\hline
\end{tabular}

AA: Axillary artery; ACHA: anterior circumflex humeral artery; BA: brachial artery; CR: case report; PBA: profunda brachii artery; PCHA: posterior circumflex humeral artery. 


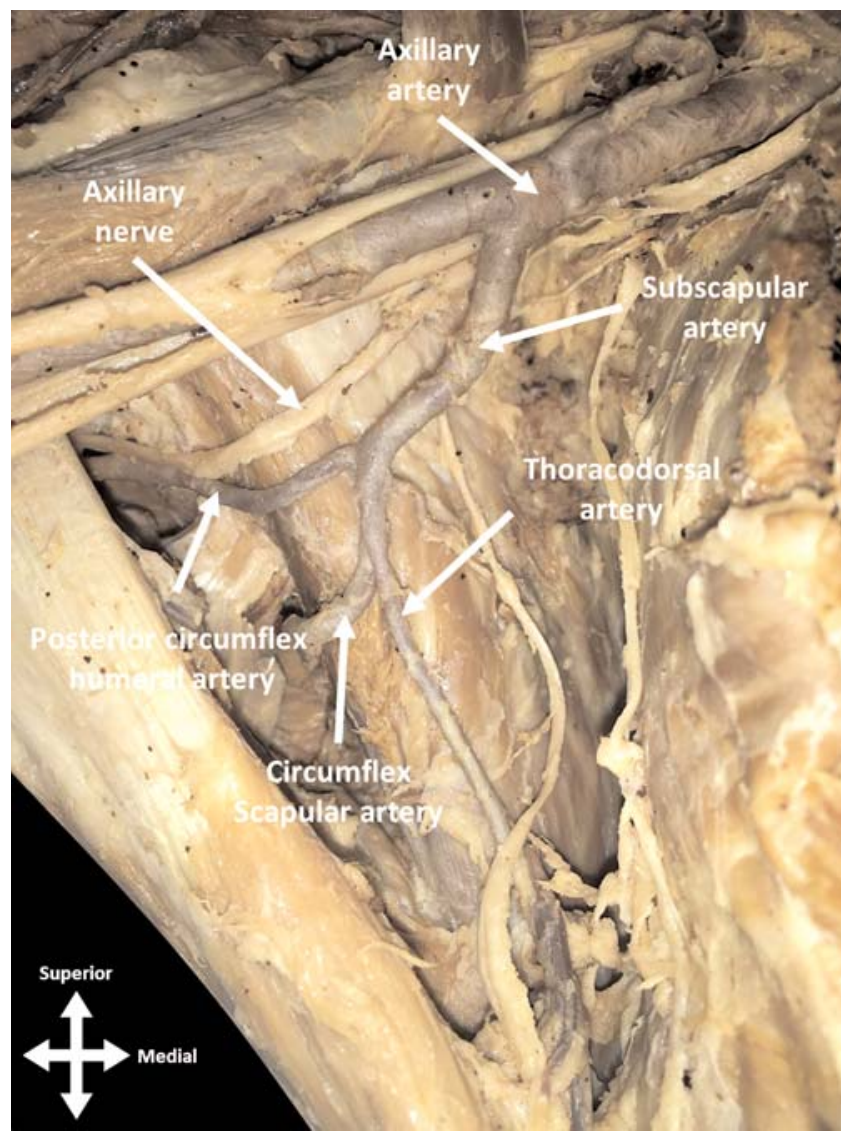

Figure 2. Anterior view of the right shoulder after dissection with exposure of the axillary artery and its branches. The posterior circumflex humeral artery is seen arising from the subscapular artery. It then courses through the quadrilateral space along with the axillary nerve.

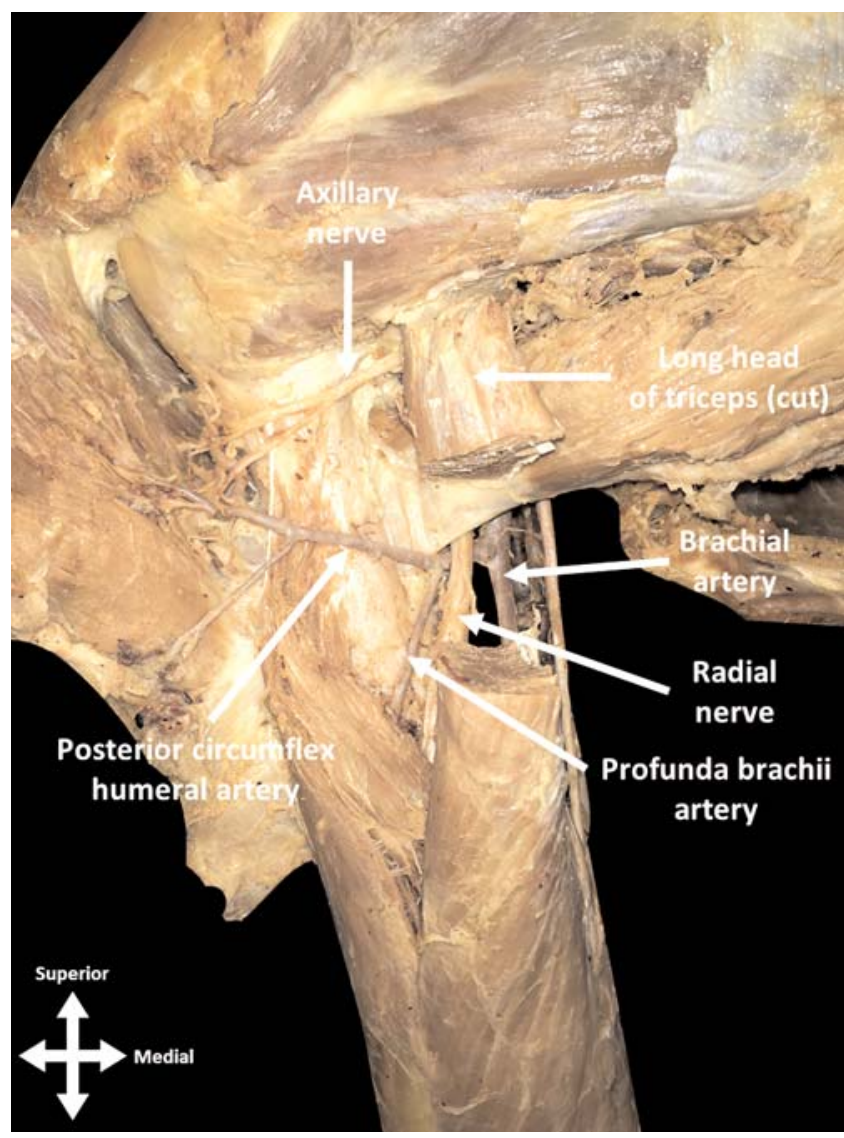

Figure 3. Posterior view of the left shoulder after dissection with exposure of the profunda brachii artery. The long head of triceps was cut to reveal the origin of the posterior circumflex humeral artery as it originates from the profundi brachii artery.

Table 2

Frequency of distribution of the origin of the PCHA.

\begin{tabular}{|c|c|c|c|c|c|c|c|c|c|}
\hline \multirow[b]{2}{*}{ Studies } & \multicolumn{9}{|c|}{ Origin of ACHA (\%) } \\
\hline & LT & SS & $\begin{array}{l}\text { 1st part } \\
\text { of } A A\end{array}$ & $\begin{array}{l}\text { 2ndpart } \\
\text { of AA }\end{array}$ & $\begin{array}{c}\text { 3rd part } \\
\text { of } A A\end{array}$ & BA & CS & PBA & Others \\
\hline Farhan and Selman ${ }^{[1]]}$ & 2 & 11 & & & & 9 & & & \\
\hline Saralaya et al..$^{[14]}$ & & & $C R$ & & & & & & \\
\hline Goldman $^{[15]}$ & & $C R$ & & & & & & & \\
\hline Lee and $\mathrm{Kim}^{[16]}$ & & & $C R$ & & & & & & \\
\hline Durgun et al. ${ }^{[17]}$ & & $C R$ & & & & & & & \\
\hline Swamy et al. ${ }^{[18]}$ & & & & $C R$ & & & & & \\
\hline Olinger and Benninger ${ }^{[8]}$ & 1.2 & & & & 77.1 & 8.4 & 12 & & \\
\hline Hartley and Marquez ${ }^{[9]}$ & & 6 & & & 56 & & & & \\
\hline Majumdar et al..$^{[19]}$ & & $C R$ & & & & & & & \\
\hline Patnaik et al. ${ }^{[5]}$ & & & & & & 2 & & 2 & \\
\hline Hattori et al. ${ }^{[10]}$ & & & & & 33.9 & & & & \\
\hline Huelke et al ${ }^{[4]}$ & & 15.2 & & & 67.5 & & & 2.8 & 2.2 \\
\hline Present study & & 10 & & & 80 & & & 10 & \\
\hline
\end{tabular}

AA: Axillary artery; BA: brachial artery; CR: case report; CS: circumflex scapular artery; LT: lateral thoracic artery; PBA: profunda brachii artery; PCHA: posterior circumflex humeral artery; SS: subscapular artery. 
PCHA may clinically contribute to trauma or surgical intervention for PHF. However, the anatomical course of the PCHA is additionally of clinical importance in relation to sports injuries. Kraan et al., ${ }^{[26]}$ reported in a systematic review in relation to PCHA aneurysms, which can lead to ischemic emboli in the upper limb, that an anatomical variation may be protective. If the PCHA is running through the quadrangular space, this poses a risk of the artery being damaged by repetitive muscle contraction as it passed through the narrow space. Interestingly, Huelke et al., ${ }^{[4]}$ have reported a rare variation in which the PCHA is observed to originate from the PBA. By following this course, the artery avoids the narrow quadrangular space for which it can be compressed from repetitive muscle contraction, i.e. in boxers, baseball players and professional swimmers. This is thought to be a protective variation of the PCHA in relation to overuse injuries in the dominant shoulder of sport professionals. This variation does not follow the classical anatomical course as it does not enter the quadrangular space. The current study has reported this variation in 10\% of the samples (Figure 3) and this may provide essential knowledge regarding risk factors for developing PCHA pathology in relation to its anatomical origin.

This study was limited by the sample size of cadavers, which may require further studies on a larger sample size. Additionally, no clinical data was available regarding clinical symptoms, if present, in relation to the anatomical variations studied.

\section{Conclusion}

Knowledge of the anatomical variations of the circumflex humeral arteries is of paramount importance in relation to pathology and surgical intervention. Understanding the possible anatomical branching pattern of the vascular structures around the shoulder is clinically relevant to help manage patients with acute shoulder injuries or pathology.

\section{Acknowledgments}

The authors would like to express their sincere gratitude to the body donors and their families. Special thanks to the staff of Anatomy at the University of Edinburgh for their support throughout the study.

\section{Conflict of Interest}

The authors certify that they have no affiliations with or involvement in any organization or entity with any financial interest (such as honoraria; educational grants; participation in speakers' bureaus; membership, employment, consultancies, stock ownership, or other equity interest; and expert testimony or patent-licensing arrangements), or non-financial interest (such as personal or professional relationships, affiliations, knowledge or beliefs) in the subject matter or materials discussed in this manuscript.

\section{Author Contributions}

ME: data collection, photography for figures, manuscript writing; AA: data collection, manuscript writing.

\section{Ethics Approval}

Cadaveric specimens were obtained with ethical approval of Anatomy, University of Edinburgh, regulated by the Human Tissue (Scotland) Act 2006.

\section{Funding}

This study did not receive any funding.

\section{References}

1. Standring $\mathrm{S}$ (Editor). Gray's anatomy: the anatomical basis of clinical practice. 41st ed. edition. New York: Elsevier Limited; 2016. p. 1562.

2. Snell RS. Clinical anatomy by regions. 9th ed. Baltimore, MD: Lippincott Williams \& Wilkins; 2012. p. 754.

3. Moore KL, Agur AMR, Dalley AF. Clinically oriented anatomy. 8th ed. Philadelphia, PA: Wolters Kluwer; 2018. p. 1153.

4. Huelke DF. Variation in the origins of the branches of the axillary artery. Anat Rec 1959;135:33-41.

5. Patnaik G, Kalsey G, Singla RK. Branching pattern of brachial artery-a morphological study. Journal of the Anatomical Society of India 2002;51:176-86.

6. Bagoji IB, Hadimani GA, Bannur BM, Patil BG, Bharatha A. A unique branching pattern of the axillary artery: a case report. J Clin Diagn Res 2013;7:2939-40.

7. Saeed M, Rufai AA, Elsayed SE, Sadiq MS. Variations in the subclavian-axillary arterial system. Saudi Med J 2002;23:206-12.

8. Olinger A, Benninger B. Branching patterns of the lateral thoracic, subscapular, and posterior circumflex humeral arteries and their relationship to the posterior cord of the brachial plexus. Clin Anat 2010;23:407-12.

9. Hartley BR, Marquez S. Tracking branching variation of the axillary artery. FASEB J Journal 2012;26(S1):722.12-722.12.

10. Hattori Y, Doi K, Sakamoto S, Satbhai N. Anatomic variations in branching patterns of the axillary artery: a multidetector-row computed tomography angiography study. J Reconstr Microsurg 2013; 29:531-6.

11. Farhan TM, Selman MO. Anatomical study of axillary artery variation. Journal of the Faculty of Medicine Baghdad 2010;52:324-7.

12. Tank PW, Grant JCB. Grant's dissector. 15th ed. Philadelphia, PA: Lippincott Williams \& Wilkins; 2013. p. 285.

13. Bhat KMR, Gowda S, Potu BK, Rao MS. A unique branching pattern of the axillary artery in a South Indian male cadaver. Bratisl Lek Listy 2008;109:587-9.

14. Saralaya V, Joy T, Madhyastha S, Vadgaonkar R, Saralaya S. Abnormal branching of the axillary artery: subscapular common 
trunk. a case report. International Journal of Morphology 2008;26: 963-966.

15. Goldman EM. Axillary artery and branch variations in an 83 year-old male Caucasian. FASEB J Journal 2008;22(S1):770.6-770.6.

16. Lee JH, Kim DK. Bilateral variations in the origin and branches of the subscapular artery. Clin Anat 2008;21:783-5.

17. Durgun B, Yücel AH, Kizilkanat ED, Dere F. Multiple arterial variation of the human upper limb. Surg Radiol Anat 2002;24:125-8.

18. Swamy RS, Rao MKG, Kumar N, Sirasanagandla S, Nelluri VM. Unusual branching pattern of axillary artery associated with the high origin of ulnar artery. Ann Med Health Sci Res 2013;3:2657.

19. Majumdar S, Bhattacharya S, Chatterjee A, Dasgupta H, Bhattacharya K. A study on axillary artery and its branching pattern among the population of West Bengal, India. Italian Journal of Anatomy and Embryology 2013;118:159-71.

20. Gerber C, Schneeberger AG, Vinh TS. The arterial vascularization of the humeral head. An anatomical study. J Bone Joint Surg Am 1990;72:1486-94.
21. Brooks CH, Revell WJ, Heatley FW. Vascularity of the humeral head after proximal humeral fractures. An anatomical cadaver study. J Bone Joint Surg Br 1993;75:132-6.

22. Lanting B, MacDermid J, Drosdowech D, Faber KJ. Proximal humeral fractures: a systematic review of treatment modalities. J Shoulder Elbow Surg 2008;17:42-54.

23. Xu J, Zhang C, Wang T. Avascular necrosis in proximal humeral fractures in patients treated with operative fixation: a meta-analysis. J Orthop Surg Res 2014;9:31.

24. Lewis WH. The development of the arm in man. Am J Anat 1902;1: 145-83.

25. Olinger A. Upper limb arteries. In: Tubbs RS, Shoja MM, Loukas $M$, editors. Bergman's comprehensive encyclopedia of human anatomic variation. 1st ed. Hoboken, NJ: John Wiley \& Sons, Inc.; 2016. p. 583-618.

26. Kraan RB, Beers L, van de Pol D, Daams JG, Maas M, Kuijer PP. A systematic review on posterior circumflex humeral artery pathology: sports and professions at risk and associated risk factors. J Sports Med Phys Fitness 2018;59:1058-67.

ORCID ID:

M. Elajnaf 0000-0001-7276-2555: A. Alashkham 0000-0003-2959-5039

deomed
Correspondence to: Abduelmenem Alashkham, PhD, MSc, MBBCh University of Edinburgh, Old Medical School, Doorway 3, Teviot Place, Edinburgh, EH8 9AG, UK

Phone: +44131650 2924

e-mail: abduelmenem.alashkham@ed.ac.uk

Conflict of interest statement: No conflicts declared.

This is an open access article distributed under the terms of the Creative Commons Attribution-NonCommercial-NoDerivs 4.0 Unported (CC BY-NCND4.0) Licence (http://creativecommons.org/licenses/by-nc-nd/4.0/) which permits unrestricted noncommercial use, distribution, and reproduction in any medium, provided the original work is properly cited. How to cite this article: Elajnaf M, Alashkham A. Variations of the circumflex humeral arteries: a cadaveric study. Anatomy 2020;14(3):171-176. 